\title{
Mushy Zone Morphology During Directional Solidification of Pb-5.8 Wt Pct Sb Alloy
}

L. Yu

Cleveland State University

Follow this and additional works at: https://engagedscholarship.csuohio.edu/encbe_facpub

$\hat{c}$ L. Ding

uevertad state Mniverialsity science and Engineering Commons

How does access to this work benefit you? Let us know!

中. Ryy risher's Statement

Cleveland State University

Copyright 2000 ASM International. This paper was published in Metallurgical and Materials

\$rakısajdtions A: Physical Metallurgy and Materials Science, Vol. 31, Issue 9, pp. 2275-2285 and

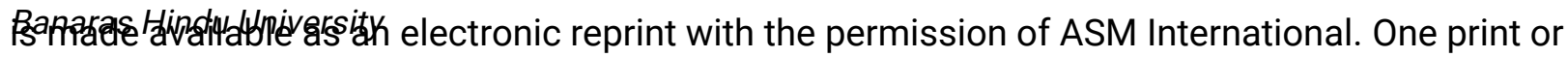
slectrianiafopewala be made for personal use only. Systematic or multiple reproduction,

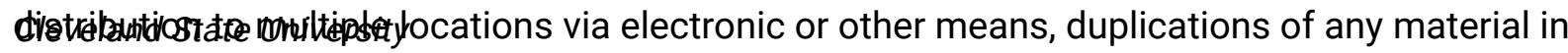
this paper for a fee or for commercial purposes, or modification of the content of this paper are prohibited.

Available on publisher's site at: http://www.springerlink.com/content/27087431520q3612/.

\section{Original Citation}

Yu, L., Ding, G.L., Reye, J., Ojha, S.N., \& Tewari, S.N. (2000). Mushy Zone Morphology During Directional Solidification of Pb-5.8 Wt Pct Sb Alloy. Metallurgical and Materials Transactions A: Physical Metallurgy and Materials Science 31, 2275-2285.

\section{Repository Citation}

Yu, L.; Ding, G. L.; Reye, J.; Ojha, S. N.; and Tewari, Surendra N., "Mushy Zone Morphology During Directional Solidification of Pb-5.8 Wt Pct Sb Alloy" (2000). Chemical \& Biomedical Engineering Faculty Publications. 21. https://engagedscholarship.csuohio.edu/encbe_facpub/21

This Article is brought to you for free and open access by the Chemical \& Biomedical Engineering Department at EngagedScholarship@CSU. It has been accepted for inclusion in Chemical \& Biomedical Engineering Faculty Publications by an authorized administrator of EngagedScholarship@CSU. For more information, please contact library.es@csuohio.edu. 


\title{
Mushy Zone Morphology during Directional Solidification of $\mathrm{Pb}-5.8 \mathrm{Wt}$ Pct Sb Alloy
}

\author{
L. YU, G.L. DING, J. REYE, S.N. OJHA and S.N. TEWARI
}

The $\mathrm{Pb}-5.8$ wt pct $\mathrm{Sb}$ alloy was directionally solidified with a positive thermal gradient of $140 \mathrm{~K}$ $\mathrm{cm}^{-1}$ at a growth speed ranging from 0.8 to $30 \mu \mathrm{m} \mathrm{s}^{-1}$, and then it was quenched to retain the mushy zone morphology. The morphology of the mushy zone along its entire length has been characterized by using a serial sectioning and three-dimensional image reconstruction technique. Variation in the cellular/dendritic shape factor, hydraulic radius of the interdendritic region, and fraction solid along the mushy zone length has been studied. A comparison with predictions from theoretical models indicates that convection remarkably reduces the primary dendrite spacing while its influence on the dendrite tip radius is not as significant.

\section{INTRODUCTION}

CEllulaR/DENDRITIC array morphologies in the mushy zone formed during directional solidification determine the pattern of solute segregation, which, in turn, determines the mechanical properties of the directionally solidified components. An extensive body of literature ${ }^{[1,2,3]}$ exists on the spacing and tip morphologies of cellular/dendritic arrays in directionally solidified transparent metal analogues, such as succinonitrile-acetone alloys. However, it has not been possible to examine these alloys for other important mushy zone characteristics, such as microsegregation across cells and dendrites, volume fraction of the solid and liquid phase in the mushy zone, and mushy zone permeability. Due to the opaque nature of the metallic alloys, in situ observation of their cellular/dendritic morphology has been possible only in thin (two-dimensional) samples using X-ray topography. ${ }^{[4]}$ For three-dimensional arrayed growth of cells and dendrites in metallic alloys, the observations are based on their directionally solidified and quenched microstructures. The quenched array tip region of the mushy zone has been used for determining the tip radius, tip temperature, and tip composition of cells and dendrites. ${ }^{[5,6]}$ Whereas, primary spacing $^{[7]}$ and microsegregation (fraction eutectic ${ }^{[8]}$ measurements are based on the directionally solidified portion of the samples. The entire mushy zone morphology, from tips of the dendrite arrays to their base, has not been systematically studied in any alloy.

Considerable theoretical attempts ${ }^{[9-12]}$ have been made to establish the fundamentals of cellular/dendritic growth. $\operatorname{Most}^{[9,10,11]}$ assumed two-dimensional, axis-symmetric, smooth-shaped cells and dendrites. Only recently has threedimensional analysis of cells/dendrites been performed by phase field methods, ${ }^{[12]}$ which can, for the first time, account for side-branch formation in dendrites. Testing of such phase field models requires integrated information on the mushy

L. YU, Graduate Student, G.L. DING, Research Associate, J. REYE, Undergraduate Student, and S.N. TEWARI, Professor, are with the Chemical Engineering Department, Cleveland State University, Cleveland, OH 44115. S.N. OJHA, formerly Visiting Professor, Chemical Engineering Department, Cleveland State University, is Professor, Metallurgical Engineering Department, Banaras Hindu University, Varanasi, India.

Manuscript submitted July 16, 1999. zone morphology that goes beyond the traditional characteristic length scales such as primary spacing and tip radius.

The purpose of this research was to characterize the entire mushy zone morphology in directionally solidified metallic alloys for both cellular and dendritic arrays, using the recently developed technique of serial sectioning and threedimensional image reconstruction. ${ }^{[13]}$ This technique allows us to render a three-dimensional view of the cellular/dendritic arrays, accurately measure characteristic length scales such as the tip radius, and investigate the variation of the other morphology factors, such as the cell/dendrite shape factor, the intercellular/dendritic hydraulic radius, and fraction solid along the mushy zone length.

Natural convection plays a significant role during the directional solidification of metallic alloys. It results in distortion of the mushy zone and clustering of the cells/dendrites in one region of the microstructure ("steepling") for alloys where solute enrichment leads to an increased melt density; an example are the aluminum-rich aluminum copper alloys. ${ }^{[5]}$ "Seepling" is most severe for growth conditions where the morphology is cellular or near the cell to dendrite transition. ${ }^{[14]}$ Natural convection produces longitudinal (parallel to the alloy growth direction) macrosegregation in alloys where solute enrichment results in reduced melt density as found in lead rich lead-tin ${ }^{[15]}$ or lead-antimony. ${ }^{[16]}$ These alloys can also produce "channel segregates" under certain growth conditions. ${ }^{[15]}$ However, if "channel segregate" formation can be avoided, then the mushy zone has a reasonably uniform morphology. ${ }^{[15,16]}$ This makes these alloys more suitable for this study, which is aimed at a detailed quantitative characterization of the entire mushy zone during directional solidification. The $\mathrm{Pb}-5.8$ wt pct $\mathrm{Sb}$ alloy was, therefore, selected for this study.

\section{EXPERIMENTAL PROCEDURE}

\section{A. Alloy Preparation and Directional Solidification}

About 24- to 30-cm-long Pb-5.8 wt pct Sb feed-stock samples were obtained by induction melting a charge (lead 99.99 wt pet purity and antimony 99.999 wt pct purity) under an argon atmosphere in a graphite crucible and pushing the melt into evacuated quartz tubes $(0.6-\mathrm{cm}$ i.d.) with the help of argon pressure. The cast alloy cylinders were extracted and placed into the quartz directional solidification 
ampoule (0.7-cm i.d., 61-cm long). The quartz ampoule was then sealed at the bottom. It was evacuated from the top and heated in the directional solidification furnace to create a 15 - to $20-\mathrm{cm}$-long melt column. Directional solidification (DS) was carried out by withdrawing the ampoule from the furnace assembly at various speeds. After 6 to $10 \mathrm{~cm}$ of directional solidification, the ampoule was quickly pulled from the furnace, and the melt column was quenched by spraying water on the ampoule surface.

Temperature profiles during directional solidification were measured by two chromel-alumel thermocouples (0.01$\mathrm{cm}$-diameter wires kept in the closed-end silica capillaries with $0.06-\mathrm{cm}$ o.d.) with their tips separated by 3 to $5 \mathrm{~cm}$ along the sample length. The steady-state thermal profile was maintained as indicated by identical thermal profiles obtained from the two thermocouples. The thermal gradient in the liquid at the liquid-solid interface during these experiments was maintained at $140 \pm 8 \mathrm{~K} \mathrm{~cm}^{-1}$.

\section{B. Metallography and Macrosegregation}

Longitudinal and transverse microstructures were observed by standard optical metallography techniques using an etchant made up of $5 \mathrm{~mL}$ nitric acid, $5 \mathrm{~mL}$ acetic acid, and $90 \mathrm{~mL}$ glycerin. Two millimeter thick slices were cut along the length of the DS sample as a function of solidification distance. These slices were chemically analyzed by atomic absorption spectroscopy for their antimony content.

\section{Serial Sectioning and Three-Dimensional Image Reconstruction}

Serial sectioning and three-dimensional image reconstruction were used to obtain morphological information about the cell/dendrite tips. The cell/dendrite tip position at the time of quench was first located by examining a longitudinal section through the sample. The sample portion containing the mushy zone was then machined out and mounted in epoxy in order to observe the microstructure on the transverse sections. The sample was located in the mount such that the quenched cell/dendrite tips were about $1 \mathrm{~mm}$ below the mount surface. A reference hole was then drilled on the transverse sections. A Leica Ultramiller, ${ }^{[17]}$ which could make serial sections and provide a surface finish suitable for optical metallography, was used to obtain transverse microstructures as a function of distance from the quenched array tips. The milled surface was lightly etched in order to reveal the microstructure. The microstructures were recorded by the help of a TV camera (which was attached to the Ultramiller) without removing the sample from the machine stage. Boundary of the reference hole was drawn on a transparent sheet mounted on the monitor. The sample was translated after each serial sectioning so that the image of the reference hole always aligned with the reference hole image drawn on the transparent sheet. This method assured alignment of the transverse images for the subsequent threedimensional rendering of the cell/dendrite tip morphology. Typically, a sample was cut at 3 to $5 \mu \mathrm{m}$ steps for a distance of about $100 \mu \mathrm{m}$ from the array tips. Then it was sectioned at 10 to $50 \mu \mathrm{m}$ steps for a distance of about $0.3 \mathrm{~mm}$ into the mushy zone. The subsequent sections were made at 100 $\mu \mathrm{m}$ intervals.
Cell or dendrite boundaries were edge tracked on various transverse sections, and their coordinates were fed into a three-dimensional rendering software, IRIS Explorer 3.5. ${ }^{[18]}$ Details of the serial sectioning and three-dimensional image reconstruction are reported elsewhere. ${ }^{[13]}$

\section{RESULTS}

\section{A. Microstructure and Macrosegregation}

Figure 1 shows typical longitudinal microstructures of directionally solidified and quenched cellular and dendritic arrays in $\mathrm{Pb}-5.8 \mathrm{wt}$ pct $\mathrm{Sb}$ alloy grown at different speeds at a thermal gradient of $140 \mathrm{~K} \mathrm{~cm}^{-1}$ in the melt at the array tips. It is apparent from this figure that the cells and dendrites are aligned nearly parallel to the alloy growth direction. With increasing growth speed, the morphology changes from cellular to dendritic. For the thermal gradient studied, the cell to dendrite transition occurs at $1.5 \mu \mathrm{m} \mathrm{s}^{-1}$.

Typical growth-speed dependence of the longitudinal macrosegregation in directionally solidified samples is shown in Figure 2, which plots $C_{s} / C_{o} v s$ fraction distance solidified $\left(f_{s}\right)$, where $C_{s}$ is the antimony content in the solid and $C_{o}$ is the original solute content of the melt. In this figure, the symbols marked by " $L$ " indicate composition of the quenched liquid portion of the specimen. For each directionally solidified specimen, the $C_{o}$ values, obtained by measuring the area under the $C_{s} v s f_{s}$ plots that included both the directionally solidified and quenched melt portions were found to be within \pm 5 pct of the composition of the precast feed stock bars obtained by chemical analysis. This figure shows that $C_{s} / C_{o}$ value increases from less than unity to values larger than unity as a function of $f_{s}$. This is an indication of extensive mixing between the interdendritic mushy zone liquid and the bulk melt ahead of the cellular/ dendritic arrays. In the absence of convection, a uniform solute content will be expected along the entire length of directionally solidified specimens (except for the initial and final transients, which would be of about the same size as the mushy zone length). Data for one as-cast feedstock sample that was similarly analyzed along the specimen length did not show longitudinal macrosegregation (this sample was not included in this figure for the sake of clarity). The extent of macrosegregation increases with decreasing growth speed. Convection is caused by density inversion in the interdendritic melt (antimony content increases towards the bottom of the mushy zone and reduces the melt density) and in the bulk melt immediately ahead of the tip because of the solutal build up. ${ }^{[19]}$ The extent of convection increases with decreasing growth speed.

\section{B. Cellular/Dendritic Array Morphology}

A series of digitized images of the dendrites on different transverse sections in the mushy zone are presented in Figure 3 as a function of distance from the quenched tip. The number at the upper-left corner indicates the distance from tip. A closer examination of these images shows that dendrites, even within their immediate neighborhood, do not have a uniform mushy zone length. Some of them lead their neighbors, and some lag behind. For example, in the image that is $14 \mu \mathrm{m}$ away from the tip, no tips are observed in the upper-left corner, marked "A" (the first image of Figure 3). 


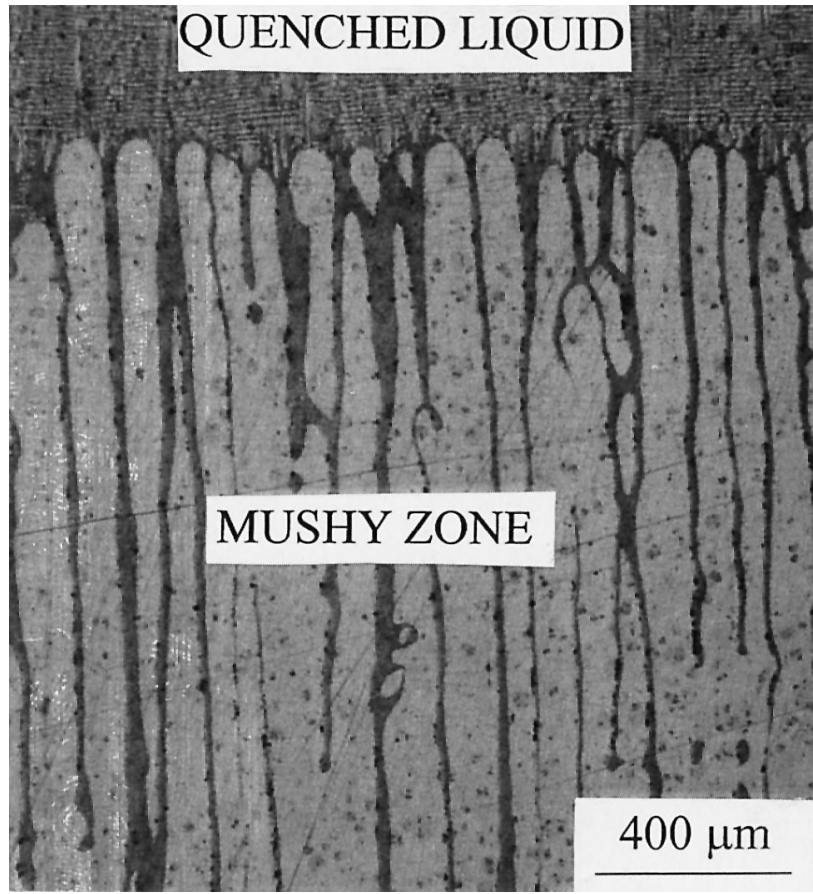

(a)

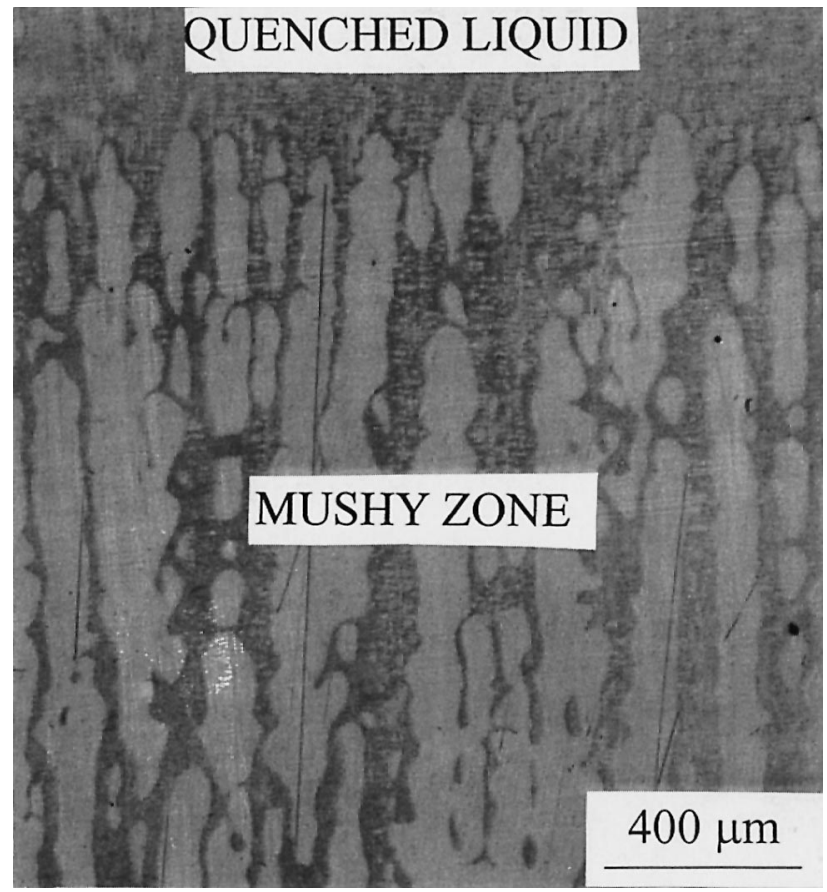

(b)

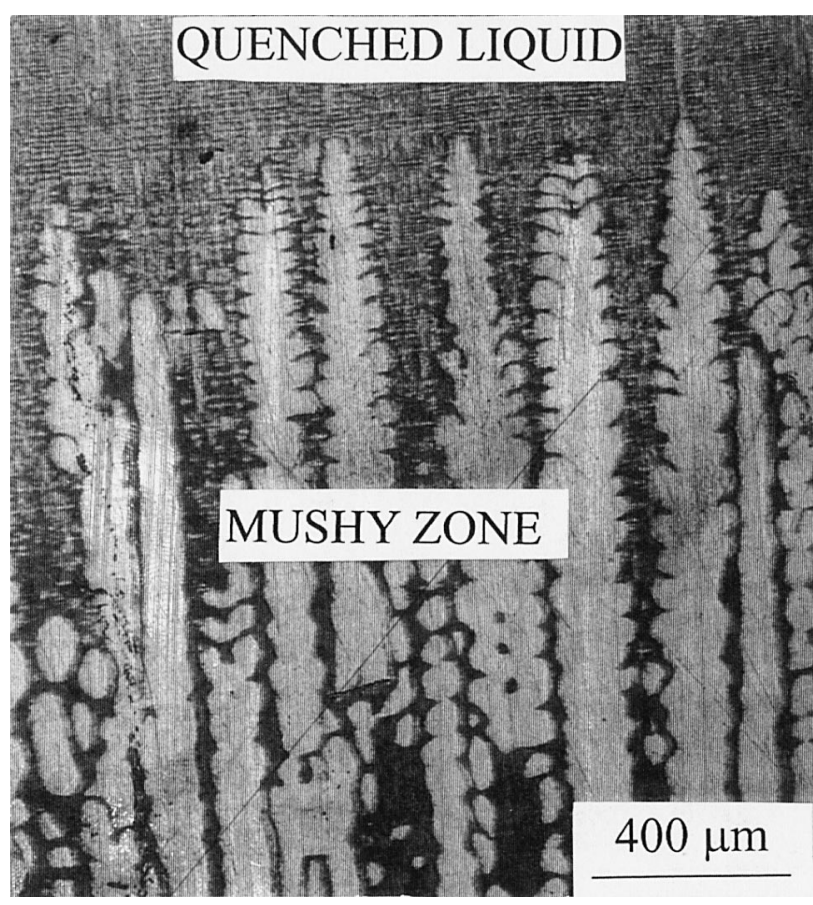

(c)

Fig. 1-Typical longitudinal microstructures of Pb-5.8 wt pct Sb alloy directionally solidified at $140 \mathrm{~K} \mathrm{~cm}^{-1}:(a)$ cellular $\left(V=0.8 \mu \mathrm{m} \mathrm{s}{ }^{-1}\right),(b)$ cellular to dendritic transition $\left(V=1.5 \mu \mathrm{m} \mathrm{s}^{-1}\right)$, and $(c)$ dendritic $\left(V=3 \mu \mathrm{m} \mathrm{s}^{-1}\right)$.

However, the same region of the transverse section (the third image of Figure 3) shows dendrites at a distance of $91 \mu \mathrm{m}$ from the leading edge of the array tips.

A three-dimensional view of the dendrite array through the mushy zone is shown in Figure 4(a). A view directly looking into the array from the tip is shown in Figure 4(b). The primary dendrites show no evidence of any rotation as shown by a nearly perfect match among the respective views of the four side lobes at more than 120 transverse sections, dendrite "B" in Figure 4(b). This would be expected for a dendrite growing along [100] crystallographic direction. The dendrites in Figure 4(a) appear to be parallel to one another. However, a slight tilt is observed. In the transverse view, when the sections of the four side lobes appear perfectly superimposed for one dendrite, the other dendrites in the immediate vicinity do not show perfect alignment. A tilt of 2 to $4 \mathrm{deg}$ is required to achieve perfect alignment of the four side branch lobes along their length. The tilt may be 


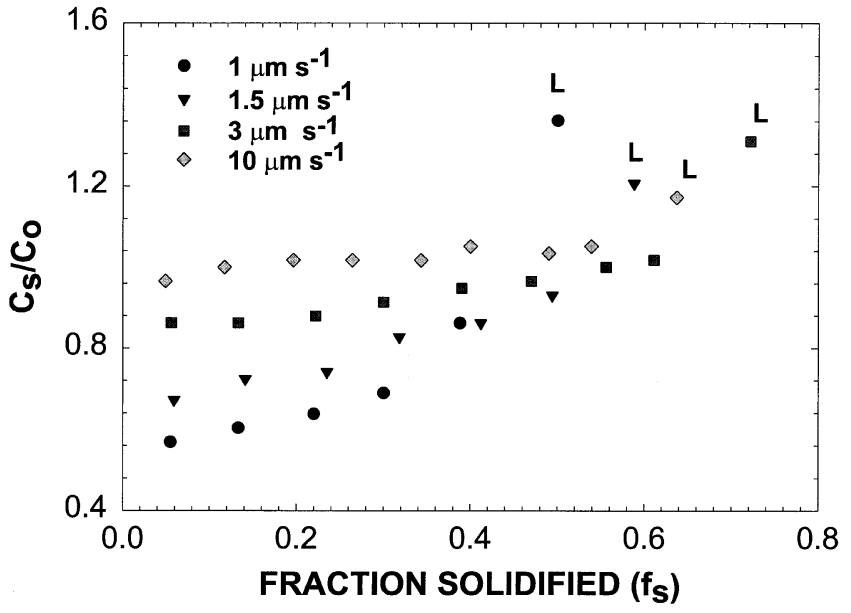

Fig. 2-Influence of growth velocity on macrosegregation along the length of directionally solidified $\mathrm{Pb}-5.8 \mathrm{wt}$ pet $\mathrm{Sb}$ alloy, $G_{1}=140 \mathrm{~K} \mathrm{~cm}$.

caused by the presence of subgrain boundaries within the samples. Such subgrain boundaries are evident in Figure 3 for the section at $1008 \mu \mathrm{m}$.

Typical transverse microstructures for the cells are shown in Figure 5. The mushy zone length of the cells within the array is also not uniform. For example, the cell " $\mathrm{C}$ " observed in the cross section at $100 \mu \mathrm{m}$ (the fifth image of Figure 5) from the tip was not visible in the same region of the transverse section at $10 \mu \mathrm{m}$ (the first image of Figure 5). There is significant coarsening of the cells along the mushy zone length. Several cells in the immediate neighborhood merge with one anoother (compare region "D" at $2964 \mu \mathrm{m}$ with the same region at $202 \mu \mathrm{m}$ in Figure 5). This behavior has been reported in directionally solidified Al-2 wt pct $\mathrm{Cu}$ alloys. ${ }^{[20]}$ Such merging was not observed for dendrites (Figure 3). It is, therefore, very important that the primary spacing, especially for the cells, be determined from transverse cross sections near the array tips and not from the microstructures in the directionally solidified portion of the samples where the apparent spacing would be much larger. It is interesting to note that the cells do not have circular cross sections, which would be expected for an axis-symmetric morphology. The dendrites, especially near their tips, were more axis-symmetric (Figure 3 ) than cells.

Three-dimensional longitudinal and transverse views of the mushy zone for cellular array are shown in Figure 6(a) and 6(b). The cells are more poorly aligned with respect to the sample translation axis as compared with the dendrites

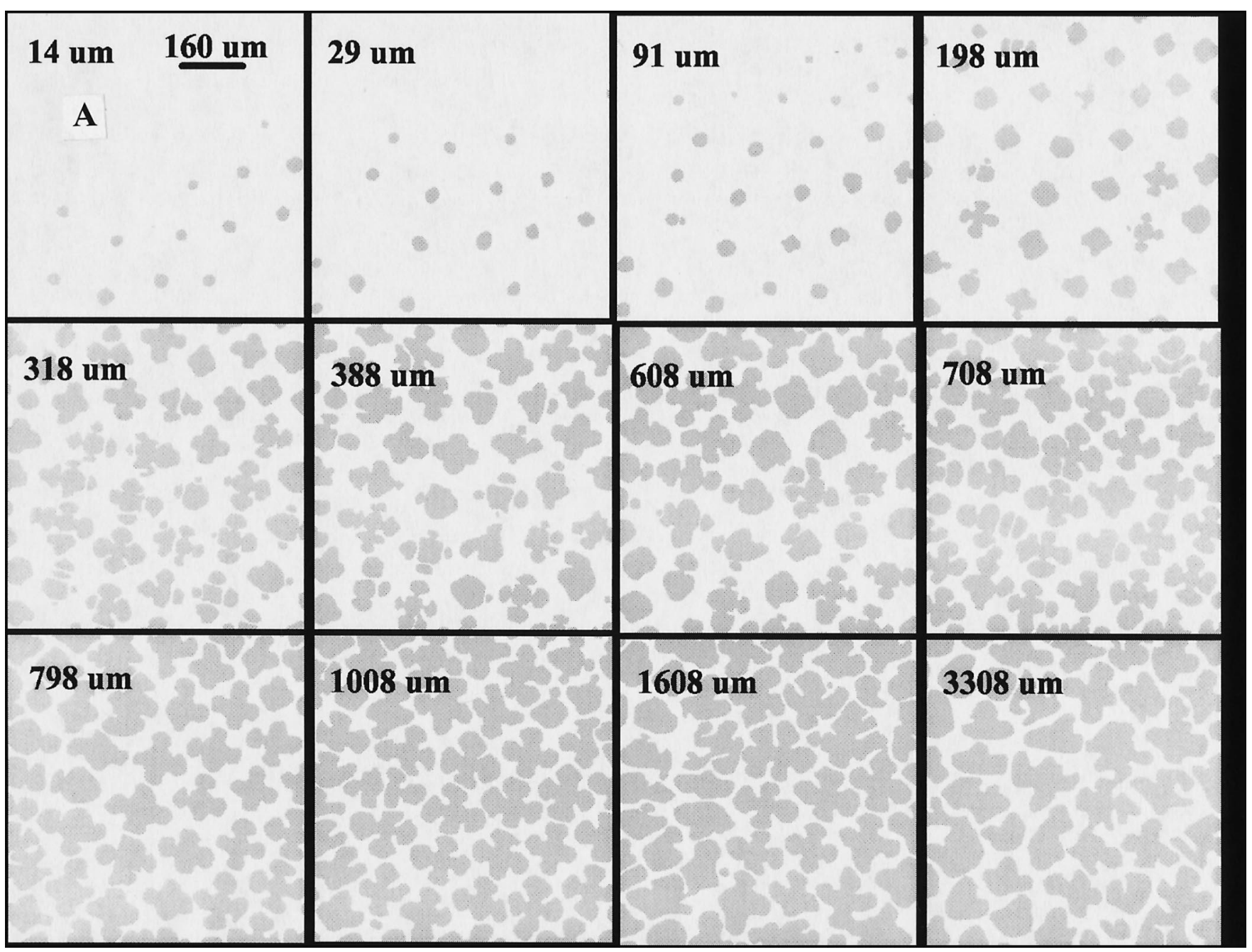

Fig. 3-Digitized images of dendrites on several transverse sections in the mushy zone as the function of distance from the quenched tip, $\mathrm{Pb}-5.8 \mathrm{wt}$ pct $\mathrm{Sb}$ alloy, $G_{1}=140 \mathrm{~K} \mathrm{~cm}^{-1}, V=3 \mu \mathrm{m} \mathrm{s}^{-1}$. 


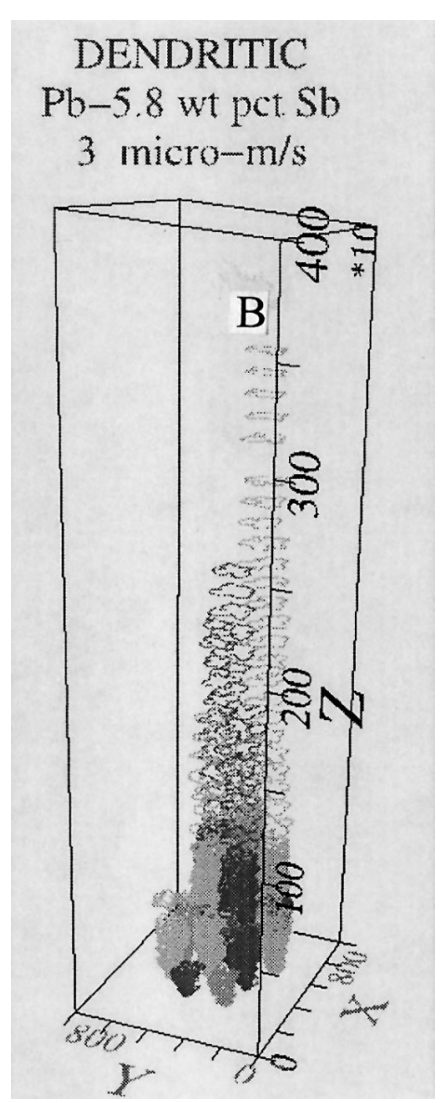

(a)

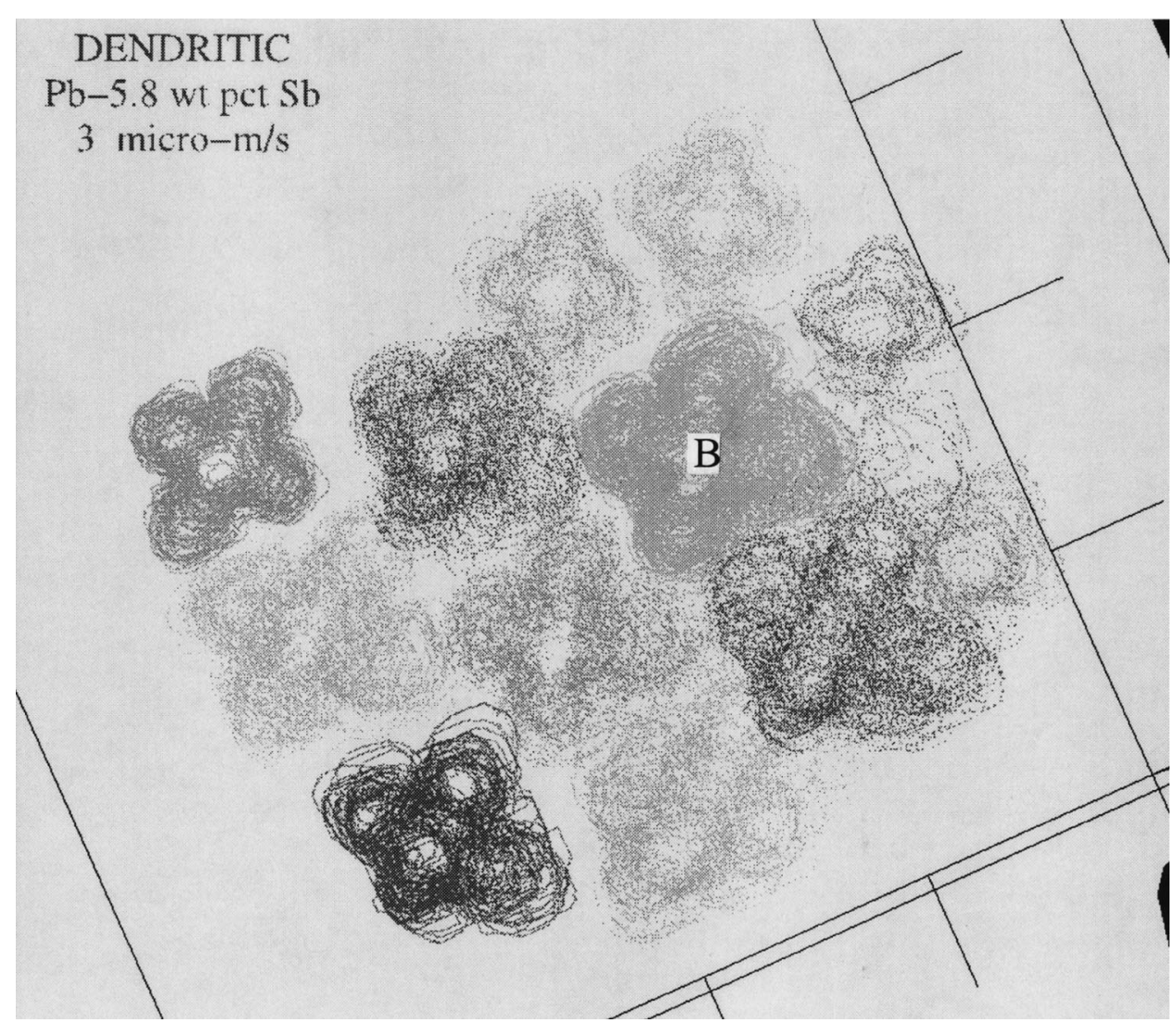

(b)

Fig. 4-Three-dimensional view of a dendritic array, $\mathrm{Pb}-5.8 \mathrm{wt}$ pct $\mathrm{Sb}$ alloy, $G_{1}=140 \mathrm{~K} \mathrm{~cm}^{-1}, V=3 \mu \mathrm{m} \mathrm{s}^{-1}$ : (a) longitudinal view and (b) transverse view.

(Figure 4(a)). The non-axis-symmetric nature of the cells is also quite evident in this figure. It suggests that cells may not have a steady-state tip morphology during directional solidification, as was observed during directional solidification of transparent succinonitrile-acetone alloys where individual cell tips were observed to fluctuate within a shape envelope. ${ }^{[21]}$ This fluctuation may arise due to competition among neighboring cells or may be caused by convection in the melt.

\section{Comparison of the Mushy Zone Characteristics between Cellular and Dendritic Arrays}

\section{Shape factor}

Figure 7 shows the variation in the shape factor of cells and dendrities in the mushy zone as a function of distance from the tip. Shape factor is defined as $4 \pi A / P^{2}$, where $A$ is the cross-sectional area of the dendrite, and $P$ is its perimeter. For a circular cross section, the shape factor would be one. It can be used to describe the cell/dendrite shape in the transverse section. The two dendrite plots in Figure 7 correspond to two different regions on the transverse sections where measurements were made along the entire mushy zone length. Good agreement between the two sets of data indicates that microstructure on any cross section is quite uniform. The shape factor for the dendrites is about 0.9 near the tips, and it slowly decreases to about 0.5 at a distance of about $700 \mu \mathrm{m}$. For a paraboloidal tip shape, the shape factor should be unity for the dendrites. The slightly smaller value of 0.9 could be an artifact introduced in the measurement due to quenching because very fine dendrites are formed on the preexisting primary dendrites during quenching. It may also be an indication that the dendrite tips are not exact paraboloids. The drastic decrease in their shape factor within the first $100 \mu \mathrm{m}$ from the tip is due to the formation and growth of side branches. For cells, the shape factor is very low, 0.7 , even at the tip, indicating that they are not semisphere at the tip and are not cylindrical as has been generally assumed. This is evident by their transverse microstructures shown in Figure 5.

\section{Hydraulic radius}

Variation in hydraulic radius of cells and dendrites as a function of distance from the tip is shown in Figure 8. Hydraulic radius is defined as $2 A_{L} / P$, where $A_{L}$ is the crosssectional area of the interdendritic liquid region, and $P$ is its perimeter. A larger hydraulic radius indicates higher permeability in the mushy zone. As indicated earlier, the two sets of data for dendrites in Figure 8 are from two different regions of the transverse sections for the same sample. Their agreement is an indication of the microstructural uniformity on any transverse section in the mushy zone. The hydraulic radius for the dendrites begins to dramatically decrease after $100 \mu \mathrm{m}$ from the tips. Within $500 \mu \mathrm{m}$ from the tip, which is about 20 pct of the mushy zone length, it dropped from a high value of about $100 \mu \mathrm{m}$ to a very low value of about $6 \mu \mathrm{m}$. This severe drop in the mushy zone permeability is caused by side-branch growing. This suggests that convection in the mushy zone is localized near the array tips to a 


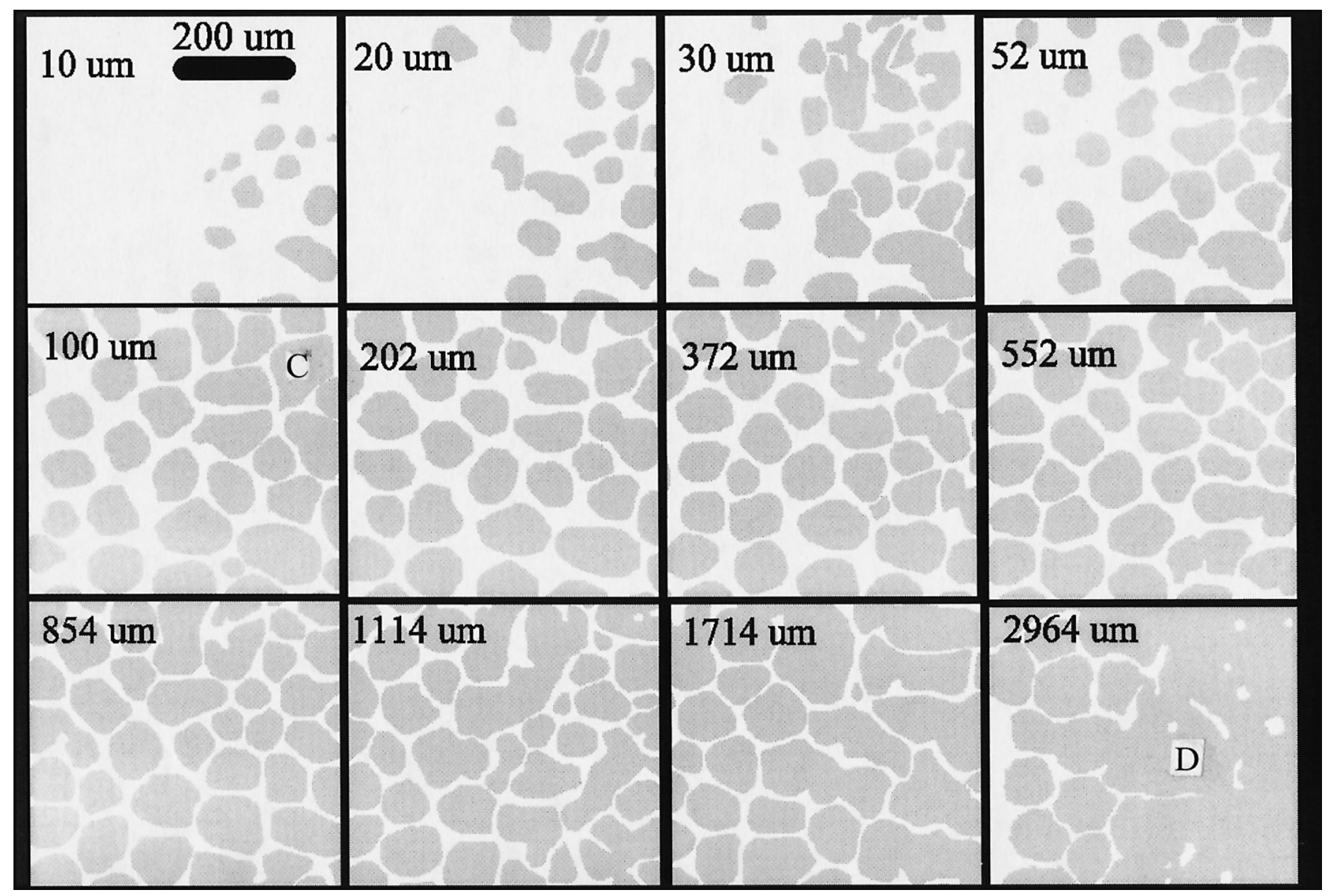

Fig. 5-Digitized images of cells on several transverse sections in the mushy zone as the function of distance from the quenched tip, $\mathrm{Pb}-5.8 \mathrm{wt}$ pct $\mathrm{Sb}$ alloy, $G_{1}=140 \mathrm{~K} \mathrm{~cm}^{-1}, V=1 \mu \mathrm{m} \mathrm{s}^{-1}$.

depth of about 20 pct of the mushy zone length. This observation is in agreement with earlier results from numerical modeling of convection during growth of dendritic arrays. ${ }^{[2]}$ The hydraulic radius for the cells is significantly smaller than dendrites (Figure 8), even in the region very close to the array tips. In the absence of side branches, the primary trunks of cells are more closely packed than the dendrites resulting in very small hydraulic radius. The very low mushy zone permeability of the cells indicates that convection would be localized only at the array tips and would not into the mushy zone.

\section{Variation of fraction solid}

Figure 9 shows the variation of fraction solid in the mushy zone as a function of distance from the tip for samples grown at $1.0,1.5$, and $3 \mu \mathrm{m} \mathrm{s}^{-1}$, respectively. The two sets of data for the 1.5 and $3 \mu \mathrm{m} \mathrm{s}^{-1}$ samples are from two regions with transverse sections at varying distance from the array tips. Their good agreement indicates a uniform distribution of fraction solid on the entire sample cross section. There is a steep increase in the fraction solid in the cells within 120 $\mu \mathrm{m}$ from the tip, as shown in Fig 9(a). For the dendrites, this increase is much slower (Figure 9(c)). The solid curves in this figure indicate theoretical predictions and will be discussed later.

\section{Primary spacing}

Figure 10(a) shows a typical distribution of nearest and higher order primary spacings for dendrites grown at $3 \mu \mathrm{m}$ $\mathrm{s}^{-1}$. Center of mass of individual cells or dendrites were identified on a cross section in the mushy zone within about $100 \mu \mathrm{m}$ from the array tips, and these were subsequently used to determine the primary spacing distribution. ${ }^{[23]}$ There is a very distinct peak corresponding to the nearest neighbors. In order to deconvolute the hidden peaks, the spacing distribution data were analyzed by a software, Peakfit $4.06,{ }^{[24]}$ using Gaussian Amplitude analysis with variable peak width following subtraction of the linear background from the data. For each Gaussian peak, the frequency $F$ is given as $F=$ $A_{0} \exp \left[-0.5\left(\left(X-A_{1}\right) / A_{2}\right)^{2}\right]$, where $X$ is the spacing, $A_{0}$ is the peak amplitude, $A_{1}$ is the peak center, and $A_{2}$ is the peak width parameter. The resulting analysis for this sample is shown in Figure 10(b). The primary spacing, as indicated by the nearest neighbor peak, for this sample is $164.6 \pm$ $4.0 \mu \mathrm{m}$.

The growth speed dependence of the primary spacings obtained in this manner is shown in Figure 11 for the cellular and dendritic samples examined in this study. The open symbols correspond to the cells, and the filled symbols are for dendrites. The error bars correspond to standard deviation. The primary spacing first increases with increasing 


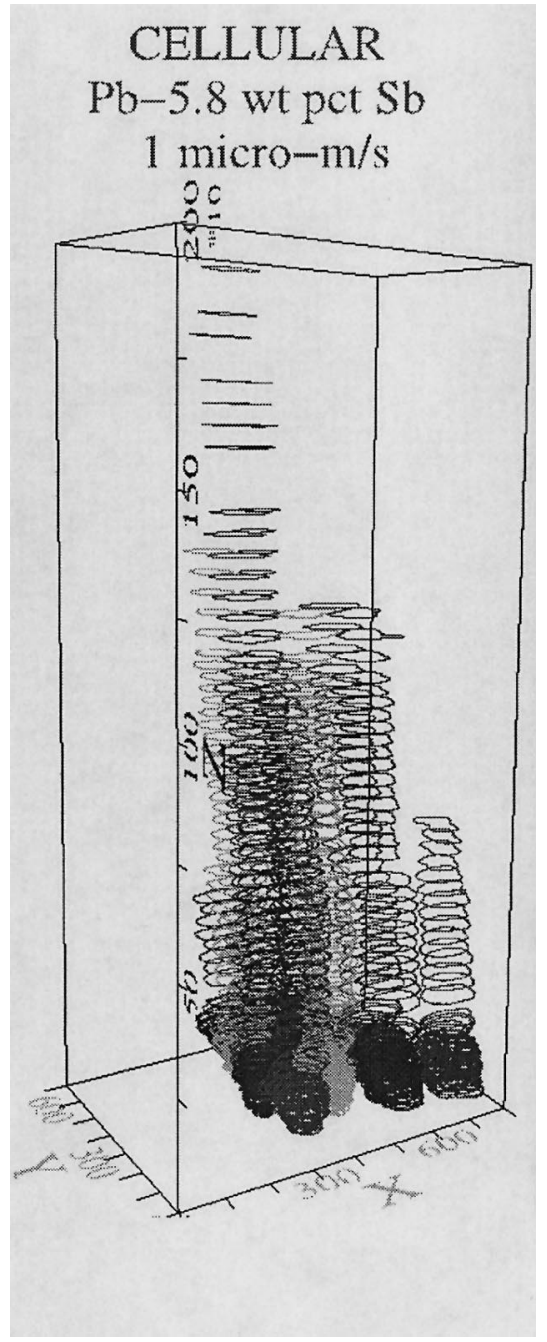

(a)

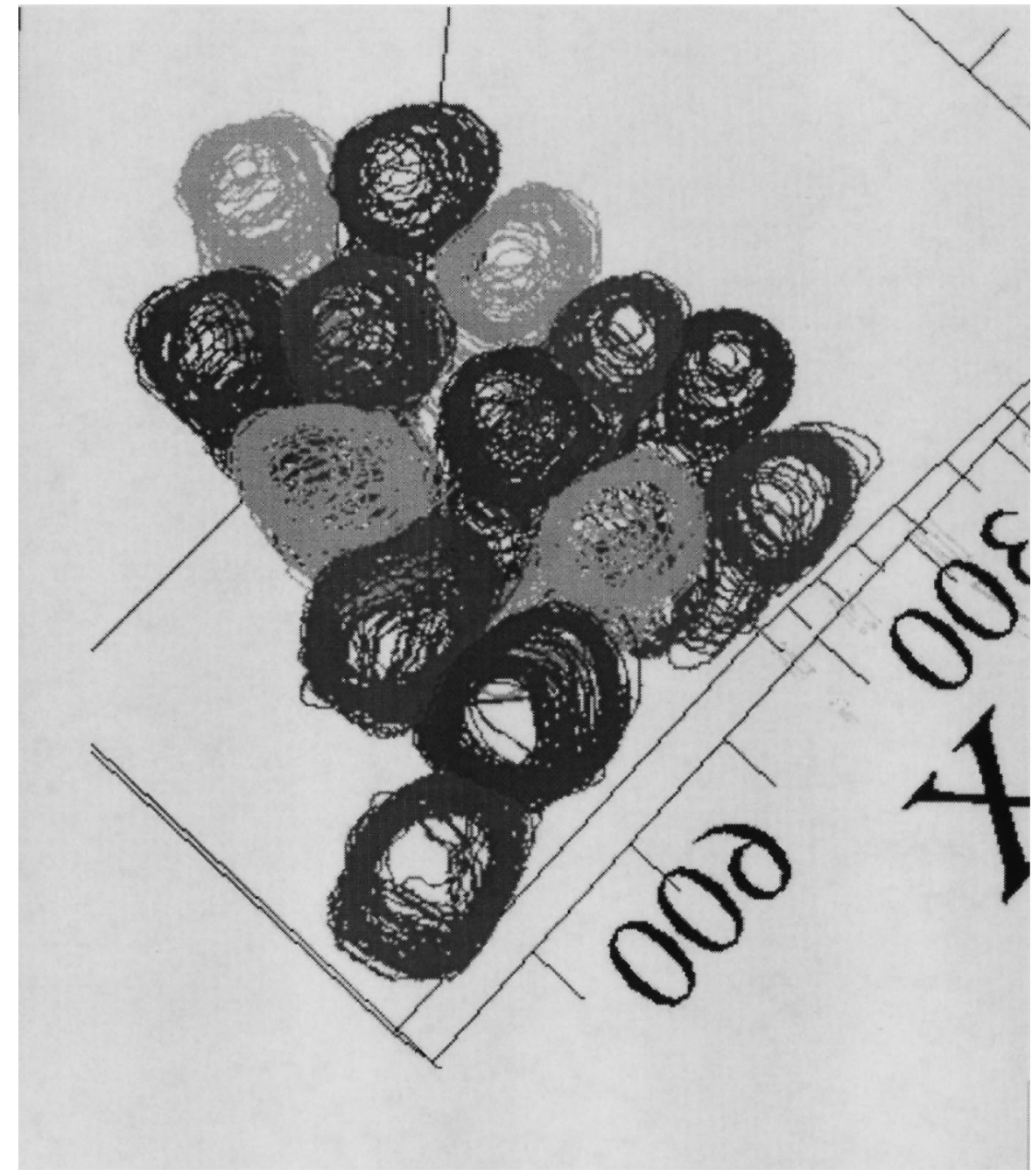

(b)

Fig. 6-Three-dimensional view of a cellular array, Pb-5.8 wt pct Sb alloy, $G_{1}=140 \mathrm{~K} \mathrm{~cm}^{-1}, V=1 \mu \mathrm{m} \mathrm{s}^{-1}$ : (a) longitudinal view and (b) transverse view.

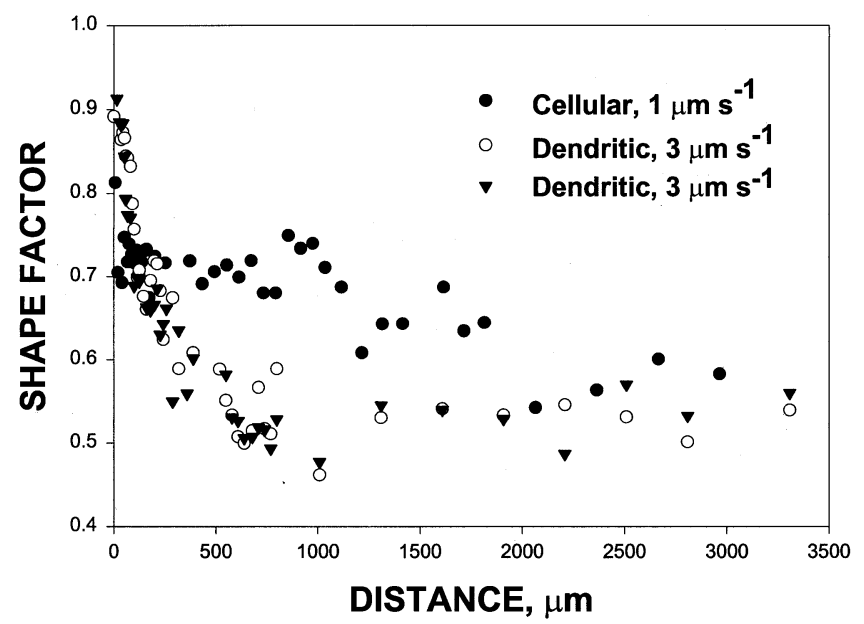

Fig. 7-Variation of the shape factor as a function of distance from the tip, $\mathrm{Pb}-5.8$ wt pet $\mathrm{Sb}$ alloy, $G_{1}=140 \mathrm{~K} \mathrm{~cm}^{-1}$.

growth speed. It begins to decrease after a peak in the vicinity of the cell to dendrite transition. This behavior has been observed in many alloys. The lines in this figure indicate theoretical predictions ${ }^{[1]}$ and will be discussed later.

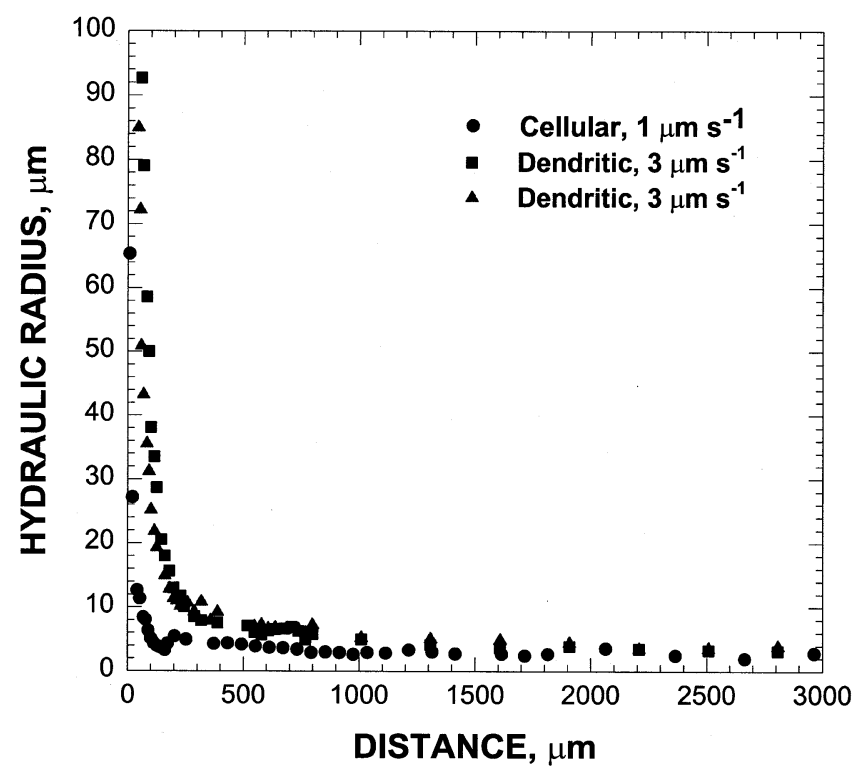

Fig. 8-Variation of the hydraulic radius as a function of distance from the tip, Pb-5.8 wt pet $\mathrm{Sb}$ alloy, $G_{1}=140 \mathrm{~K} \mathrm{~cm}^{-1}$. 

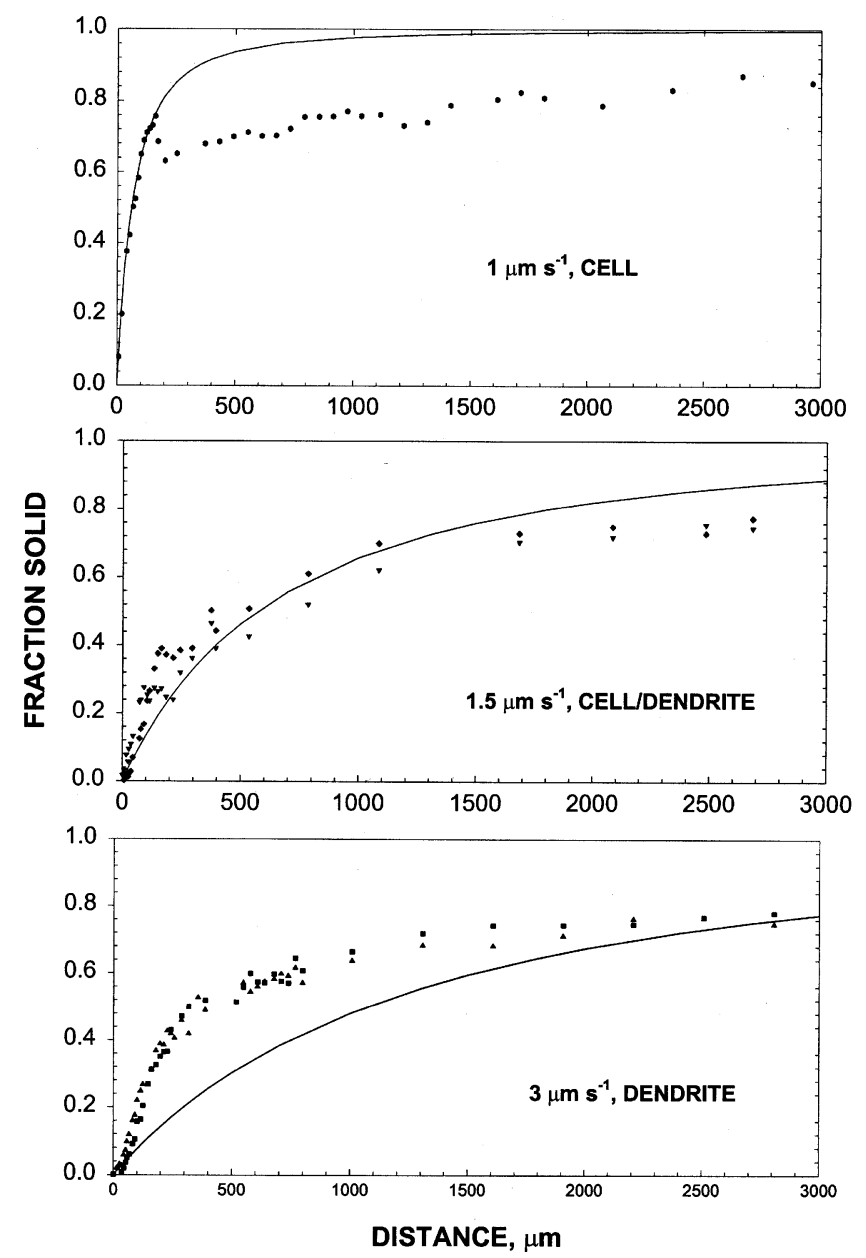

Fig. 9-Fraction solid in the mushy zone, comparison with Hunt-Lu model, $\mathrm{Pb}-5.8$ wt pet $\mathrm{Sb}$ alloy, $G_{1}=140 \mathrm{~K} \mathrm{~cm}^{-1}$.

\section{DISCUSSION}

\section{A. Fraction Solid versus Distance from the Array Tip}

Hunt $^{[25]}$ presented the following relationship between the fraction solid in the mushy zone, $g_{S}$, vs the distance from the cellular/dendritic array tip, $x$ :

$$
\begin{aligned}
\left(1-g_{S}\right)^{k-1}= & {\left[\left(C_{t}+G x / m\right)(1-k)+D G / m V\right] / } \\
& {\left[C_{t}(1-K)+D G / m V\right] }
\end{aligned}
$$

where $D$ is the solute diffusion coefficient in the liquid, $k$ is the equilibrium partition coefficient, $m$ is the liquidus slope, $G$ is the thermal gradient in the liquid, $V$ is the growth speed, and $C_{t}$ is the tip composition in the liquid. In order to calculate $g_{S}$ vs $x$ from this equation, we have used $C_{t}$ predicted by the cell/dendrite model of Hunt-Lu. ${ }^{[1]}$ The theoretical predictions thus obtained using the following values: $G=140 \mathrm{~K} \mathrm{~cm}^{-1}$, the initial alloy composition $C_{0}=$ 5.8 wt pct $\mathrm{Sb}, k=0.4^{[26]}, m=6.8 \mathrm{~K} / \mathrm{wt}$ pct $\mathrm{Sb}^{[26]}$, capillarity $\Gamma=0.089 \mu \mathrm{m} \mathrm{K}^{[27]}$, and $D_{1}=3 \times 10^{-5} \mathrm{~cm}^{2} \mathrm{~s}^{-1[28]}$ (indicated by the solid curves in Figure 9). Figure 9(a) shows that for cells (growth speed of $1 \mu \mathrm{m} \mathrm{s}^{-1}$ ), the theoretical prediction is in excellent agreement with the experiment near the tip. However, it deviates remarkably after a distance

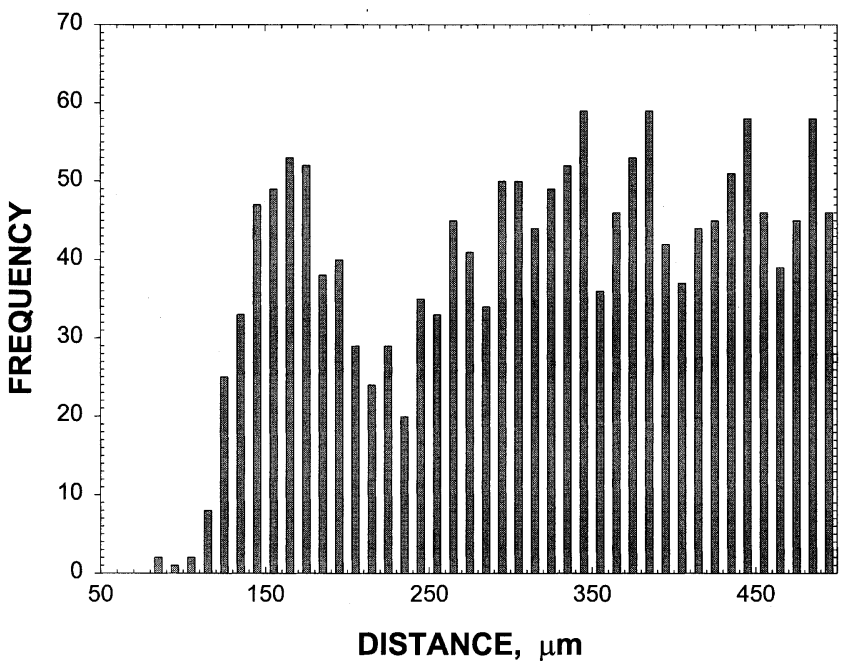

(a)

( $P k=$ Gauss Amp, $B g=$ Linear, $r^{2}=0.768$ )

Peak1: $164.6 \pm 4.0 \mu \mathrm{m}, 31.1 \pm 6.8 \mu \mathrm{m}$, Peak2: $306.9 \pm 6.7 \mu \mathrm{m}$, Peak3: $436.1 \pm 14.8 \mu \mathrm{m}$

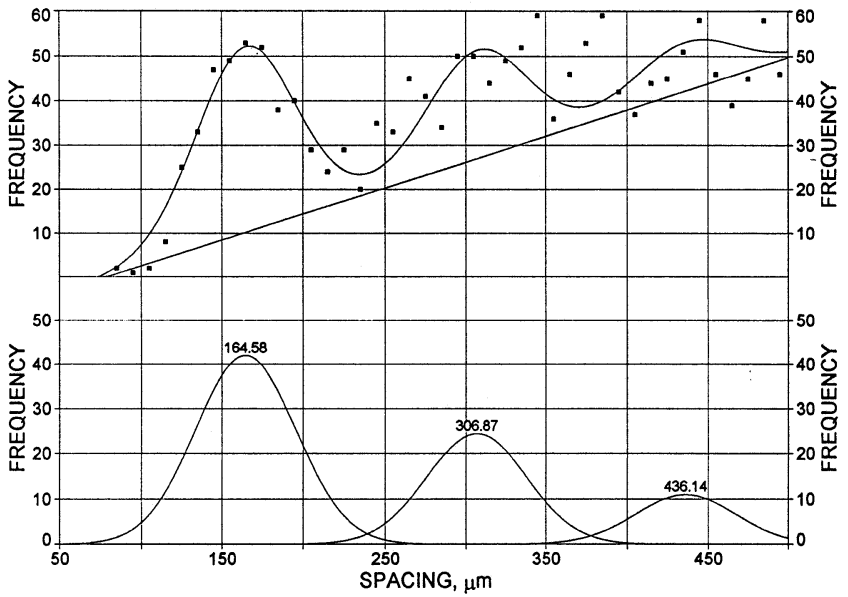

(b)

Fig. 10-Primary spacing distribution and regression analysis obtain the nearest neighbor spacings, Pb-5.8 wt pct Sb alloy, $G_{1}=140 \mathrm{~K} \mathrm{~cm}^{-1}, V=$ $1 \mu \mathrm{m} \mathrm{s}^{-1}$. (a) Histogram of typical dendrite spacings including the nearest and higher order spacings and $(b)$ regression fit with a Gaussian amplitude analysis (linear background substraction).

of about $200 \mu \mathrm{m}$ from the tip. For the cellular/dendritic transition (growth speed of $1.5 \mu \mathrm{m} \mathrm{s}^{-1}$, Figure 9(b)), the prediction is in good agreement with the experimental data for most of the mushy zone length. Whereas, for the dendrites, Figure 9(c) (growth speed of $3 \mu \mathrm{m} \mathrm{s}^{-1}$ ), the agreement is poor throughout the mushy zone length.

The discrepancies between theory and experiment may be attributed to the growth of solid on the preexisting primary dendrites in the mushy zone during quenching. The quench rates involved during our experiments were measured to be about $35 \mathrm{~K} \mathrm{~s}^{-1}$. During quenching, the mushy zone morphology should evolve by the following process. First, rapid growth of solid occurs on the preexisting primary dendrites. This is followed by nucleation and growth of fine dendrites in the supercooled melt. The fine dendritic network thus formed impinges on the surface of primary dendrites and 


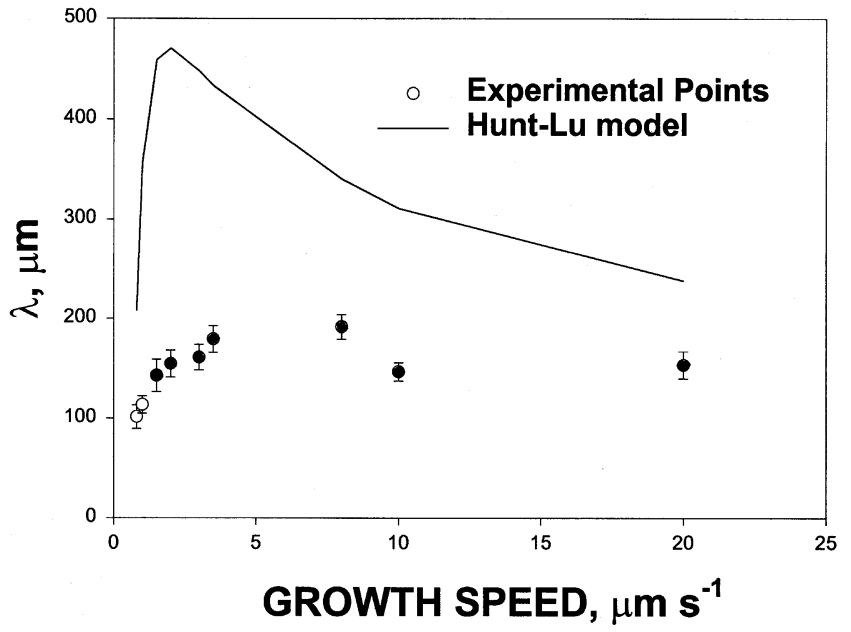

Fig. 11-Growth speed dependence of primary spacings in directionally solidified $\mathrm{Pb}-5.8$ wt pet $\mathrm{Sb}$ alloy, $G_{1}=140 \mathrm{~K} \mathrm{~cm}^{-1}$.

retards their growth. Finally, the eutetic liquid within the fine interdendritic regions solidifies. This eutectic defines the cellular/dendritic profiles used in measuring the fraction solid in the mushy zone. The experimentally determined fraction solid values would be expected to be higher than those existing during directional solidification. The deviation should be highest near the dendrite tips and decreases towards the base of dendrites. ${ }^{[29]}$ It may be suggested that this effect is responsible for the discrepancy between the experimentally observed data and the theoretically predicted behavior shown Figure 9(c) for the dendritic sample grown at $3 \mu \mathrm{m} \mathrm{s}^{-1}$. However, it fails to explain the behavior shown in Figure 9(a) for the cellular sample grown at $1 \mu \mathrm{m} \mathrm{s}^{-1}$. The experimentally obtained fraction solid values are smaller than the theoretically predicted ones for the cellular sample.

The discrepancy may also be attributed to convection and side-branch formation not included in the theoretical analysis. Convection produces longitudinal macrosegregation (Figure 2). Solute content of the melt at the time of quench is, therefore, higher than 5.8 wt pct $\mathrm{Sb}$ assumed in the preceding fraction solid analysis. Replacing $\mathrm{C}_{0}$ with these higher values (indicated as "L" in Figure 2) decreases the predicted fraction solid values. Convection is also known to stabilize the liquid-solid interface against morphological stability. ${ }^{[30]}$ It, therefore, may also delay the onset of side branch formation. However, at this stage, it is not clear how these factors influence the amount of fraction solid in the mushy zone. The low gravity experiments would be able to determine whether convection is the key factor responsible for the discrepancy.

\section{B. Comparison of Primary Spacings with Hunt-Lu Model and Role of Convection in Reducing the Primary Spacings for Cellular and Dendritic Arrays}

The numerical model presented by Hunt and $\mathrm{Lu}^{[11]}$ is also used to compare with the experimentally determined primary spacings in Figure 11. According to the model, the following hold.

$$
\text { For cells: } \begin{aligned}
\lambda^{\prime}= & 8.18 k^{-0.485} V^{\prime-0.29}\left(V^{\prime}-G^{\prime}\right)^{-0.3} \\
& \Delta T_{S}^{\prime-0.3}\left(1-V^{\prime}\right)^{-1.4}
\end{aligned}
$$

where $\Delta T_{S}^{\prime}=\frac{G^{\prime}}{V^{\prime}}+a+(1-a) V^{\prime 0.45}-\frac{G^{\prime}}{V^{\prime}}\left(a+(1-a)^{0.45}\right)$

$$
a=5.273 \times 10^{-3}+0.5519 k-0.1865 k^{2}
$$

For dendrites: $\lambda^{\prime}=0.15596 V^{\prime}\left({ }^{a-0.75)}\left(V^{\prime}-G^{\prime}\right)^{0.75} G^{\prime-0.6028}\right.$ where $a=-1.131-0.1555 \log _{10}\left(G^{\prime}\right)-0.7589 \times 10^{-2}$ $\left[\log _{10}\left(G^{\prime}\right)\right]^{2}$

Here, $G^{\prime}=G \Gamma k / \Delta T_{0}^{2}, V^{\prime}=V \Gamma k /\left(D \Delta T_{0}\right), \lambda^{\prime}=\lambda \Delta T_{0} /$ $(\Gamma k)$, and $\lambda$ is primary spacing. The other parameters are the same as those in Eq. [1]. It should be pointed out that Equations [2a] and [2b] represent the lower limit of the predicted primary spacings.

As shown in Figure 11, the experimentally measured primary dendritic spacings are much smaller than theoretical predictions. As mentioned previously, the Hunt-Lu model does not take into account convection around the array tips and in the interdendritic region. Because convection is expected to influence the solutal profiles at the tip and the composition gradient in the interdendritic melt, the primary spacings are expected to be influenced by convection. As presented in our earlier work, ${ }^{[19]}$ convection around the array tips can be represented by a parameter, $\left[g\left(C_{t}-C_{0}\right) D_{t} /\right.$ $\left.V C_{0}\right]^{0.5}$, where $g$ is the gravitational acceleration. Figure 12(a) plots the ratio of experimentally measured primary

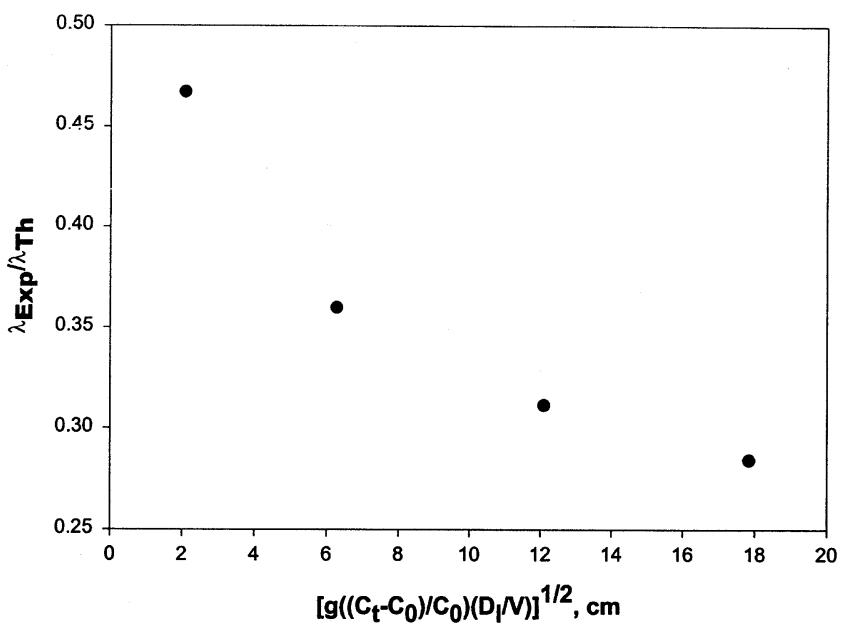

(a)

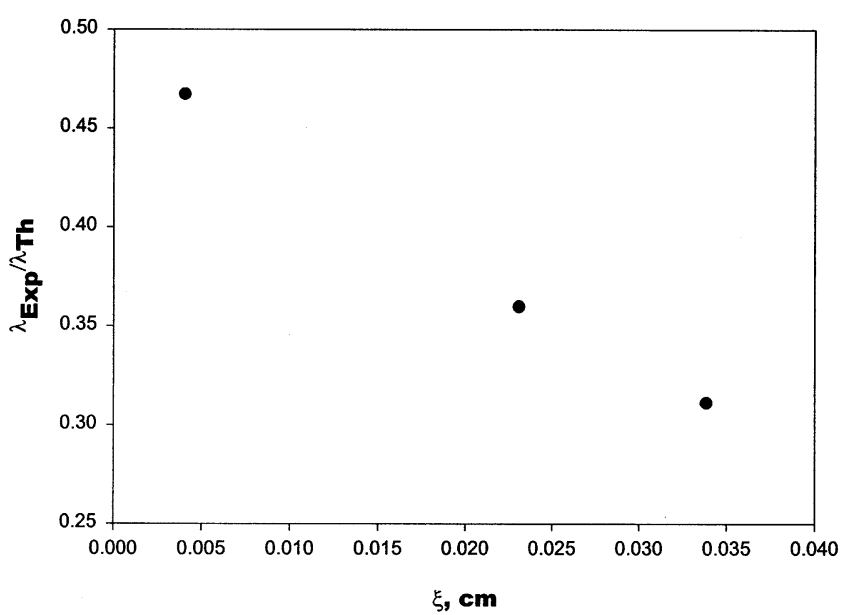

(b)

Fig. 12-Influence of convection on the primary spacings in directionally solidified $\mathrm{Pb}-5.8$ wt pct Sb alloy, $G_{1}=140 \mathrm{~K} \mathrm{~cm}^{-1}$ : (a) convection around the tip and $(b)$ convection in the interdendritic region. 
spacing $\left(\lambda_{\text {exp }}\right)$ and that predicted by the Hunt-Lu model $\left(\lambda_{\text {th }}\right)$ as a function of this parameter. We have used $C_{t}$ predicted by the Hunt-Lu model in order to calculate this parameter. The extent of decrease in primary dendrite spacing is indicated by the ratio, $\left(\lambda_{\text {exp }}: \lambda_{\text {th }}\right)$, which is directly related to the increasing value of this parameter. A decrease in the primary dendrite spacing due to convection has also been observed in $\mathrm{Pb}-\mathrm{Sn}^{[15]}$ and $\mathrm{Al}-\mathrm{Cu}^{[31,32]}$ alloys.

In order to explain the influence of convection in the interdendritic region on primary spacing, Doupouy et al. ${ }^{[33]}$ introduced a convection parameter $\zeta$ given below

$$
\xi=B \beta_{c} g G X^{*}\left|m_{L}\right|^{-1} \nu^{-1} V^{-1} f_{L}^{2} \lambda^{2}
$$

where

$$
\begin{aligned}
f_{L} & =\left[G X^{*} /\left|m_{L}\right|\left(C_{\infty}-C_{\infty}^{*}\right)+1\right]^{-1 /(1-k)} \\
X^{*} & =\min \left[\frac{\left|m_{L}\right|\left(C_{\infty}-C_{\infty}^{*}\right)(1-k)}{G(1+k)}, \frac{H}{2}, \frac{\left|m_{L}\right|\left(C_{\infty}^{* *}-C_{\infty}\right)}{G}\right] \\
C_{\infty}^{*} & =\frac{D G[1-(1-k) \Delta]}{\mathrm{R}\left|m_{L}(1-k)\right|} \\
C_{\infty}^{* *} & =C_{\mathrm{E}}-\frac{D G}{V\left|m_{L}\right|} \Delta \\
\Delta & =\min \left(1 \frac{\mathrm{R} \delta}{D}\right)
\end{aligned}
$$

Here, $B$ is a constant equal to $3 \times 10^{-4}, C_{E}$ is the eutectic composition in the equilibrium phase diagram, $\nu$ is the kinematic viscosity, $\delta$ is the convective solute boundary layer, and the other parameters are the same as those in Eqs. [1] through [2]. In order to calculate this convection parameter, primary spacing $\lambda$ and the convective solute boundary layer $\delta$ should be known in advance. The spacing $\lambda$ can be obtained either experimentally or theoretically. Here, we take the experimental data of $\lambda$ given in Figure 11. We calculate $\delta$ using the following equation:

$$
k_{\mathrm{eff}}=k /[k+(1-k) \exp (-\delta R / D)]
$$

where $k_{\text {eff }}$ is the effective solute partition coefficient, which was experimentally determined ${ }^{[16]}$ from longitudinal macrosegregation. The ratio $\lambda_{\exp } / \lambda_{t h}$ in function of this convection parameter $\xi$ is plotted in Figure 12(b). This plot indicates that convection remarkably reduces primary dendrite spacing. This observation is in agreement with low gravity experiments $^{[31,32]}$ where primary spacings were observed to be about 4 times larger in the low gravity specimens as compared with those grown terrestrially. It should be pointed out, however, that the experimentally observed dendrite tip radii in $\mathrm{Pb}-5.8 \mathrm{wt}$ pct specimens ${ }^{[13]}$ are in reasonable agreement with the theoretical predictions by the Hunt-Lu model. ${ }^{[1]}$ This observation suggests that, at least for the dendritic morphologies, the primary dendrite spacing and dendrite tip radius may be two independent length scales, not directly related to each other, as has been proposed recently. ${ }^{[34]}$ It is also possible that convection, while minimally influencing the dendrite tip radii, significantly suppresses the growth of side branches thus causing large decrease in the primary spacing. Low gravity directional solidification and quench experiments where the dendrite tip morphology and primary dendrite spacing are measured simultaneously would be required to identify the exact mechanism. Such experiments are presently planned.

\section{CONCLUSIONS}

The following conclusions can be drawn from this study where entire mushy zone morphology, from the tip of the cellualr/dendritic array to its base, was examined in directionally solidified and quenched $\mathrm{Pb}-5.8 \mathrm{wt}$ pct $\mathrm{Sb}$ alloy.

1. The hydraulic radius measurements along the mushy zone length indicate that convection for the cellular arrays are limited to the melt in the immediate vicinity of the array tips. For the dendrites, convection extends to a depth of about 20 pct of the mushy zone length.

2. Shape factor analysis along the mushy zone length indicates that cells are not axis-symmetric as generally assumed. Dendrites are significantly more axis-symmetric compared to cells.

3. Convection in these alloys causes longitudinal macrosegregation and results in significantly reduced primary dendrite spacing compared with that expected from theoretical models based on diffusive transport. However, the dendrite tip radii are not as adversely affected by convection. This suggests that while the tip radius may be an important length scale for determining the primary spacing for cells, the side-branch formation and its growth may play a more significant role in determining the primary spacing for dendrites.

\section{ACKNOWLEDGMENTS}

Support for this research was provided by NASAMicrogravity Science and Applications Division and NASA-Marshall Space Flight Center. Help from Professors David R. Poirier and Rohit Trivedi is gratefully acknowledged.

\section{REFERENCES}

1. S.H. Han and R. Trivedi: Acta Metall. Mater, 1994, vol. 42, pp. 25-41.

2. K. Somboonsuk, J.T. Mason, and R. Trivedi: Metall. Trans. A, 1984 , vol. 15A, pp. 967-75.

3. G.L. Ding, W.D. Huang, X. Huang, X. Lin, and Y.H. Zhou: Acta Mater, 1996, vol. 44, pp. 3705-09.

4. G. Grange, J. Gastaldi, C. Jourdan, and B. Billia: J. Cryst. Growth, 1995, vol. 151, pp. 192-99.

5. Y. Miyata, T. Suzuki, and J. Uno: Metall. Trans. A, 1985, vol. 16A, pp. 1799-1805.

6. M.H. Burden and J.D. Hunt: J. Cryst. Growth, 1974, vol. 22, pp. 109-16.

7. G. An and L. Liu: J. Cryst. Growth, 1987, vol. 80, pp. 383-92.

8. J.A. Sarreal and G.J. Abbaschian: Metall. Trans. A, 1986, vol 17A, pp. 2063-73.

9. J.A. Warren and J.S. Langer: Phys. Rev. E, 1993, vol. 47, pp. 2702-12.

10. B.J. Spencer and H.E. Huppert: Acta Mater., 1998, vol. 46, pp. 2645-62. 
11. J.D. Hunt and S.Z. Lu: Metall. Mater. Trans. A, 1996, vol. 27A, pp. 611-23.

12. A. Karma and W.J. Rappel: J. Cryst. Growth, 1997, vol. 174, pp. 54-64.

13. L. Yu, G.L. Ding, J. Reye, S.N. Ojha, and S.N. Tewari: Metall. Mater. Trans. A, 1999, vol. 30A, pp. 2463-72.

14. S.N. Tewari and M.A. Chopra: Microgravity Sci. Technol. III, 1990, vol. 2, pp. 99-106.

15. S.N. Tewari and R. Shah: Metall. Mater. Trans A, 1996, vol. 27A, pp. 1353-62.

16. S.N Ojha, G.L. Ding, L. Yu, J. Reye, and S.N. Tewari: Metall. Mater. Trans. A, 1999, vol. 30A, pp. 2167-71.

17. Leica Ultramiller is a product of Leica Inc., Deerfield, IL.

18. IRIS Explorer is a product of The Numerical Algorithms Group Ltd., Chicago, IL.

19. S.N. Tewari, R. Shah, and M.A. Chopra: Metall. Trans. A, 1993, vol. 24A, pp. 1661-69.

20. R.M. Sharp and A. Hellawell: J. Cryst. Growth, 1970, vol. 6, pp. $253-$ 60; 1971, vol. 11, pp. 77-91.

21. H. Song and S.N. Tewari: Metall. Mater. Trans. A, 1996, vol. 27A, pp. 1111-19.

22. J.C. Heirich, S. Felicelli, P. Nandarpurkar, and D.R. Poirier: Metall. Trans. B, 1989, vol. 20B, pp. 883-91.
23. S.P. O'Dell, G.L. Ding, and S.N. Tewari: Metall. Mater. Trans. A, 1999, vol. 30A, pp. 2159-65.

24. PeakFit is a product of AISN Software Inc., Chicago, IL.

25. J.D. Hunt: Solidification Processing and Casting of Metals, The Metals Society, London, 1979, Book 192, pp. 3-11.

26. Metals Handbook, 8th ed., ASM, Metals Park, OH, 1961, vol. 8, p. 329.

27. S.D.E. Cheveigne, C. Guthmann, and P. Kurowski: J. Cryst. Growth, 1988, vol. 92, pp. 616-28.

28. K. Niwa, M. Shimoji, S. Kado, Y. Watanabe, and T. Yokokawa: Trans. AIME, 1957, vol. 209, pp. 96-101.

29. S.R. Pati and J.E. Morral: Metall. Trans. A, 1986, vol. 17A, pp. 360-62.

30. S.N. Tewari and M.A. Chopra: J. Cryst. Growth, 1992, vol. 118, pp. 183-92.

31. H. Yu, K.N. Tandon, and J.R. Cahoon: Metall. Mater. Trans. A, 1997, vol. $28 \mathrm{~A}$, pp. $1245-50$.

32. M.D. Dupouy, D. Camel, and J.J. Favier: J. Cryst. Growth, 1993, vol. 126 , pp. $480-88$.

33. M.D. Dupouy, D. Camel, and J.J. Favier: Acta Metall., 1989, vol. 37, pp. 1143-57.

34. B.J. Spencer and H.E. Huppert: J. Cryst. Growth, 1999, vol. 200, pp. 287-96. 